\title{
Clinical and Economic Effects of a Pharmacist-Administered Antiretroviral Therapy Adherence Clinic for Patients Living with HIV
}

\author{
Thomas J. Dilworth, PharmD; Pamela W. Klein, PhD; \\ Renée-Claude Mercier, PharmD, PhC, BCPS-AQID; Matthew E. Borrego, PhD; \\ Bernadette Jakeman, PharmD, BCPS, AAHIVP; and Steven D. Pinkerton, PhD
}

\begin{abstract}
BACKGROUND: Pharmacists have demonstrated the ability to improve patient adherence to antiretroviral therapy (ART).

OBJECTIVE: To determine the clinical and economic effects of a pharmacist-administered ART adherence clinic for patients living with human immunodeficiency virus (HIV).

METHODS: This pilot study with a pretest-posttest design examined the effect of a pharmacy adherence clinic on patient HIV viral load and CD4 count over a 6-month period. Patients with documented adherence problems were referred to the clinic. The pharmacist counseled patients at baseline and met with patients 1-2 weeks, 6 weeks, 3 months, and 6 months after starting ART. A societal perspective net cost analysis of the pharmacy adherence clinic was conducted to assess the economic efficiency of the intervention.
\end{abstract}

RESULTS: Twenty-eight patients were enrolled in the study, and 16 patients reached completion. Median HIV RNA significantly decreased from 48,000 copies $/ \mathrm{mL}$ (interquartile range $[\mathrm{IQR}]=16,750-139,000$ ) to undetectable ( $<20$ copies $/ \mathrm{mL}$ ) at 6 months for all study participants who completed the full intervention $(P=0.001)$. In the 3 months following the intervention, we estimated that it prevented approximately 0.13 secondary HIV infections among the sexual partners of the 16 participants who completed the intervention. The total cost of the intervention was $\$ 16,811$ ( $\$ 1,051$ per patient), which was less than the future savings in averted HIV-related medical care expenditures $(\$ 49,702)$.

CONCLUSIONS: A pharmacy adherence clinic that focused on early and sustained ART adherence interventions helped patients with documented medication adherence problems achieve an undetectable HIV RNA. The intervention was highly cost saving, with a return of nearly $\$ 3$ in future medical care savings per dollar spent on the intervention.

J Manag Care Spec Pharm. 2018;24(2):165-72

Copyright $\odot 2018$, Academy of Managed Care Pharmacy. All rights reserved.

\section{What is already known about this subject}

- Adherence to human immunodeficiency virus (HIV) antiretroviral therapy (ART) yields quality of life and survival benefits to the person living with HIV and reduces the chance of transmission of HIV to other individuals.

Adherence counseling, before and after ART initiation, has been shown to improve ART adherence.

Multidisciplinary care teams that include pharmacists have a positive effect on ART adherence in HIV-infected patients

\section{What this study adds}

This study demonstrated that a pharmacist-led ART adherence clinic operating within a multidisciplinary care clinic can help HIV-infected patients with documented medication adherence problems achieve HIV viral suppression.

In addition to the positive clinical effect, this intervention was highly cost saving, with a return of $\$ 2.96$ in future medical care savings for each dollar spent on the adherence intervention.

Under conservative assumptions of the durability of this intervention, the adherence clinic also showed significant prevention of HIV transmission to the partners of the adherence clinic participants.

$\perp \mathbf{V}$ early all persons living with human immunodeficiency virus (HIV) who adhere to antiretroviral therapy (ART) active against their virus attain an undetectable HIV RNA viral load $\left(<50\right.$ cells $\left./ \mathrm{mm}^{3}\right)$. Early ART initiation and viral suppression, or maintaining an undetectable HIV viral load, is critical to the health and longevity of persons living with HIV (PLWH) ${ }^{1,2}$ Moreover, PLWH who achieve an undetectable viral load are less likely to transmit HIV to their sexual partners than are PLWH with unsuppressed virus. ${ }^{3}$ Viral suppression therefore has significant benefits for the individual patient and for public health. Unfortunately, only 30\% of the approximately 1.2 million PLWH in the United States have achieved viral suppression. ${ }^{4}$

Successful virologic suppression and immune reconstitution requires patients to remain approximately 95\% adherent to their prescribed ART regimens. ${ }^{5}$ Given the high level of ART adherence required to achieve and maintain long-term viral suppression, innovative mechanisms are needed to improve ART adherence. Pharmacists have specialized knowledge of medication use and adherence strategies that may be applied to the clinical management of HIV-infected patients. In addition, many pharmacists may welcome the opportunity to play an expanded role in HIV patient care. ${ }^{6}$

Previous research has reported the positive effects that pharmacists can have on patient CD4 counts, viral loads, and/or ART adherence..$^{7-12}$ Although evidence suggests that early initiation and subsequent adherence to ART regimens result in the greatest patient-level benefit, only 2 studies have measured the 
effect of early adherence interventions by pharmacists on ART adherence and/or clinical outcomes. ${ }^{13,14}$ A systematic review of the effect of pharmacists on HIV treatment outcomes called for cost-effectiveness analyses of pharmacist interventions to be performed..$^{15}$ However, there is a paucity of data describing the cost-effectiveness of pharmacist interventions aimed at improving HIV treatment outcomes. ${ }^{16,17}$ Moreover, the effect of pharmacist-directed adherence interventions on subsequent HIV transmission is unknown.

The purpose of this study was to (a) evaluate the clinical effect (CD4 counts and viral load) of a pharmacist-led ART adherence clinic that focused on early and sustained adherence counseling and (b) assess the economic efficiency from a societal perspective of this adherence intervention.

\section{Methods}

\section{Study Setting}

A pharmacist-led ART adherence clinic was held 2 half-days per week at the University of New Mexico Truman Health Services (THS), a primary care clinic providing multidisciplinary services to approximately 1,200 HIV-infected patients. Pharmacists did not work in the clinic outside of the 2 halfdays per week on which the adherence clinic was held. The adherence clinic was staffed by licensed pharmacist clinicians with prescriptive authority who provided medication adherence counseling to patients referred to the clinic by their primary care providers (PCPs).

THS PCPs referred patients to the adherence clinic for 1 or more of the following reasons: (a) initiation or reinitiation of ART; (b) ART failure, defined by a viral load $>400$ copies $/ \mathrm{mL}$ at 24 weeks or following previous viral suppression; (c) high risk for treatment failure; (d) potential or diagnosed adverse drug reaction; or (e) other adherence or pharmaceutical care issues, as determined by the PCP. Patients at high risk for treatment failure included those who had previously failed to adhere to ART or other medications, as well as patients with polypharmacy, a busy life schedule, active substance abuse, mental illness such as depression, and/or homelessness.

\section{Study Participants}

Adherence clinic patients were eligible for study inclusion if they were (a) referred to the clinic by their PCPs for medication adherence concerns between December 1, 2011, and June 1, 2013; (b) aged $\geq 18$ years; (c) without HIV dementia as determined by their PCPs; (d) consented to participation in the study; and (e) were able to read and understand English. This study was approved by the University of New Mexico Human Research Review Committee and conforms to the Declaration of Helsinki.

Sociodemographic and clinical characteristics of participants were recorded from the electronic medical record and patient interviews at baseline and included age, gender, race/ ethnicity, HIV risk factor, ART adherence barriers, highest level of education completed, and any comorbid psychiatric conditions. Participants also completed the Substance Abuse and Mental Illness Symptoms Screener (SAMISS) questionnaire to screen for mental illness and/or substance abuse. The SAMISS is part of the standard of care in the adherence clinic and has been shown to be a good initial screening tool for substance abuse and mental illness in an outpatient HIV clinic. ${ }^{18}$

\section{Adherence Intervention}

The adherence clinic was designed to ensure a regularly scheduled, initial patient follow-up by a pharmacist, allowing for early identification and management of ART-related side effects and adherence barriers following ART initiation or reinitiation, in order to improve long-term medication adherence and clinical outcomes. ${ }^{19}$ The focus on early and sustained adherence counseling was applied to all patients initiating ART during the study period, regardless if they had been prescribed ART in the past. In this context, "early" is used in reference to each patient's ART initiation during the study period. The initial adherence clinic visit lasted approximately 1 hour, after which participants were prescribed ART. Patients returned to the adherence clinic for 30-minute follow-up visits with the pharmacist at 1-2 weeks, 6 weeks, 3 months, and 6 months. Standard-of-care visits with PCPs at the THS did not occur until at least 6 weeks after ART initiation. Participants were allowed a grace period of \pm 1 week when making follow-up appointments.

Pharmacists in the adherence clinic focused their efforts on medication and disease state education. During each appointment, pharmacists performed the following as indicated or appropriate: medication reconciliation; screening for opportunistic infection prophylaxis; assessing patient adherence to ART; screening for ART adherence barriers; managing ART side effects and drug interactions; discussing patient CD4 counts, HIV viral loads, and the goals of ART therapy; using motivational interviewing techniques to encourage ART adherence; using patient recall and repetition rather than informational handouts; ordering laboratory tests and immunizations; providing management recommendations to PCPs; developing patient ART regimens with the PCPs; prescribing and/or refilling medications as necessary; and making referrals to specialists.

\section{Statistical Analysis}

Baseline patient-level sociodemographic and clinical characteristics were compared between the entire study population and the subpopulation of participants who completed the final 6-month follow-up visit to assess differential loss to follow-up using Pearson's chi-square test and the Wilcoxon signed-rank test. Wilcoxon signed-rank tests were used to compare participants' CD4 counts and HIV viral load obtained at ART initiation (baseline) and 6 weeks, 3 months, and 6 months after ART initiation. Statistical analyses were performed using SPSS version 20.0 (IBM, Armonk, NY). 


\section{Economic Analyses}

The net cost analysis was conducted from the societal perspective and included a valuation of patient time and travel expenses, as well as costs incurred by the adherence clinic to implement the intervention. ${ }^{20}$ All costs were expressed in 2015 U.S. dollars. Univariate sensitivity analyses and scenario analyses were conducted on key variables.

The cost to the THS of implementing the adherence intervention included salaries and fringe benefits for the pharmacists and receptionists who staffed the clinic, together with a 25\% clinic operations overhead charge, which also included costs related to any social workers or supportive services to assist with obtaining ART. The time pharmacists spent with adherence clinic patients was obtained from study records. An additional 40 minutes of pharmacist time was added to each patient encounter (50 minutes for the initial encounter) to account for time pharmacists spent reviewing patient records before each appointment and recording notes after the encounter. Clinic receptionists spent an estimated 10 minutes checking in each patient and scheduling follow-up appointments.

Patient records were used to determine residential ZIP codes, which then were used to estimate a patient's travel distance and time to the clinic using Google Maps. Patient transportation costs were calculated using the government reimbursement rate of $\$ 0.575$ per mile. ${ }^{21}$ Total travel time consisted of a patient's driving time plus 20 additional minutes to park, walk from the clinic parking area to the clinic, and then walk back again. Time at the clinic included the actual time spent receiving the adherence intervention from the pharmacist; 5 minutes to check-in before the clinic appointment and 5 minutes after to schedule the next appointment; and 10 minutes of wait time. Time spent by patients traveling to and from the clinic and time spent at the clinic was valued at the New Mexico minimum wage. We valued participants' time at minimum wage based on the low per capita income of Albuquerque residents (average per capita income of $\$ 20,000$ per year) and the large proportion (41.7\%) of HIV-positive Ryan White Program enrollees in New Mexico who were below 200\% of the federal poverty level. ${ }^{22}$

The cost analysis adopted an intent-to-treat approach in which the total intervention cost estimate included costs for all study patients $(n=28)$, regardless of whether they completed the full intervention. The effectiveness analysis conservatively assumed that patients who failed to complete the intervention received no benefit from the intervention. The average cost per patient who completed the intervention also was calculated.

The economic analyses focused on the HIV prevention benefits of the ART adherence intervention, a main goal of which was to help patients with detectable virus reduce their viral load to undetectable levels and then maintain it there. Consistent with a modeling study by Granich et al. (2009) ${ }^{23}$ and with the findings of the HIV Prevention Trials Network
052 study, ${ }^{3}$ our analysis assumed that PLWH who maintain an undetectable viral load through adequate ART adherence are $84 \%-96 \%$ less likely than PLWH with detectable virus to transmit HIV to a sex partner during a given time period-that is, the HIV transmission rate is $84 \%-96 \%$ smaller for PLWH with undetectable virus than for those with detectable virus. ${ }^{24}$ While this HIV transmission rate pertains directly to sexual HIV transmission, evidence suggests that ART is also associated with reduced HIV transmission among persons who inject drugs..$^{25}$ Given the small number of injection drug users in this study sample, our analysis assumed an 84\%-96\% reduction in transmission for all patients.

The analysis used an HIV transmission rate model to estimate the number of secondary HIV infections that would be expected among each study participant's sex partners during the 3-month period directly following the 6-month follow-up clinic visit. ${ }^{26}$ Two different estimates of the expected number of secondary infections were calculated for each participant with undetectable virus at the 6-month follow-up: the first estimate, $\mathrm{S}_{1}$, assumed that the participant would maintain an undetectable viral load throughout the 3-month period, whereas the second estimate, $S_{2}$, assumed that, had the participant not received the adherence intervention, his or her viral load would have remained at detectable levels. The total number of secondary HIV infections prevented by the intervention then was estimated as $\mathrm{A}=\mathrm{N} *\left(\mathrm{~S}_{2}-\mathrm{S}_{1}\right)$, where $\mathrm{N}$ denotes the number of study participants with undetectable viral load at the 6-month follow-up.

The corresponding savings in averted future HIV-related medical care expenditures and lost quality-adjusted life-years (QALYs) were estimated using previously described methods. ${ }^{27}$ Each secondary HIV infection prevented by the intervention saves society the lifetime medical care costs, $\mathrm{T}$, associated with treating a case of HIV infection. The net cost of the intervention is therefore $C_{\text {net }}=C_{\text {intv }}-A * T$, where $C_{\text {intv }}$ is the total cost of the intervention from an intention-to-treat perspective. ${ }^{28}$ If the net cost is negative (i.e., the monetized benefits of the intervention exceed its implementation cost) then the intervention is considered cost saving.

\section{Results}

Twenty-eight THS patients were screened for the study and subsequently enrolled (Table 1). Most participants were male (76.4\%) and Caucasian (28.6\%) or Hispanic (39.3\%). The most common risk factor for HIV among study participants was being a man who had sex with other men (53.6\%). The most common reason patients were referred to the adherence clinic was previous nonadherence to ART (35.7\%). Thus, $64.3 \%$ of patients were treatment naive. More than $78 \%$ of participants screened positive for mental illness on the SAMISS, and 28.6\% of participants screened positive for substance abuse issues. All participants who screened positive on the SAMISS had at least 1 psychiatric comorbidity diagnosed by a physician. 


\section{TABLE 1 Participant Characteristics}

\begin{tabular}{|c|c|c|c|c|}
\hline \multirow[b]{2}{*}{ Age (years), median (IQR) } & \multicolumn{2}{|c|}{$\begin{array}{l}\text { Full Study } \\
\text { Sample } \\
(\mathrm{N}=28)\end{array}$} & \multicolumn{2}{|c|}{$\begin{array}{l}\text { Intervention } \\
\text { Completers } \\
(\mathrm{n}=16)\end{array}$} \\
\hline & & $(24-45)$ & 28 & $(24-39)$ \\
\hline Male, n (\%) & 20 & $(71.4)$ & 11 & $(68.8)$ \\
\hline \multicolumn{5}{|l|}{ Race/ethnicity, n (\%) } \\
\hline White & 8 & $(28.6)$ & 4 & $(25.0)$ \\
\hline Hispanic & 11 & $(39.3)$ & 6 & $(37.5)$ \\
\hline African American & 3 & $(10.7)$ & 2 & $(12.5)$ \\
\hline Native American & 4 & $(14.3)$ & 3 & $(18.8)$ \\
\hline Other & 2 & $(7.1)$ & 1 & $(6.3)$ \\
\hline \multicolumn{5}{|l|}{ HIV risk factor, $\mathrm{n}(\%)$} \\
\hline MSM & 15 & $(53.6)$ & 8 & $(50.0)$ \\
\hline Heterosexual contact & 11 & $(39.3)$ & 6 & $(37.5)$ \\
\hline IDU & 2 & $(7.1)$ & 2 & $(12.5)$ \\
\hline \multicolumn{5}{|l|}{ ART adherence barriers, n (\%) } \\
\hline Previous ART nonadherence & 10 & $(35.7)$ & 4 & $(25.0)$ \\
\hline Physician referral & 5 & $(17.5)$ & 2 & $(12.5)$ \\
\hline Previous medication nonadherence & 3 & $(10.7)$ & 2 & $(12.5)$ \\
\hline Polypharmacy & 1 & $(3.6)$ & 1 & $(6.3)$ \\
\hline Busy life schedule & 1 & (3.6) & 1 & $(6.3)$ \\
\hline Active substance abuse & 1 & $(3.6))$ & 1 & $(6.3)$ \\
\hline Homelessness & 1 & $(3.6)$ & 0 & $(0.0)$ \\
\hline$>1$ ART adherence barrier & 6 & $(21.4)$ & 5 & $(31.3)$ \\
\hline \multicolumn{5}{|l|}{ Psychiatric diagnoses, n (\%) } \\
\hline Depression & 11 & $(39.3)$ & 7 & $(43.8)$ \\
\hline Depression and anxiety & 4 & $(14.3)$ & 3 & $(18.8)$ \\
\hline Depression or anxiety with PTSD & 4 & $(14.3)$ & 2 & $(12.5)$ \\
\hline Bipolar or other mood disorder & 3 & $(10.7)$ & 2 & $(12.5)$ \\
\hline No psychiatric diagnosis & 6 & $(21.4)$ & 2 & $(12.5)$ \\
\hline \multicolumn{5}{|l|}{ SAMISS, n (\%) } \\
\hline $\mathrm{SA}(+) / \mathrm{MH}(+)$ & 7 & $(25.0)$ & 4 & $(25.0)$ \\
\hline $\mathrm{SA}(+) / \mathrm{MH}(-)$ & 1 & $(3.6)$ & 1 & $(6.3)$ \\
\hline $\mathrm{SA}(-) / \mathrm{MH}(+)$ & 15 & $(53.6)$ & 10 & $(62.5)$ \\
\hline $\mathrm{SA}(-) / \mathrm{MH}(-)$ & 5 & $(17.9)$ & 1 & $(6.3)$ \\
\hline CD4 count (cells/mm³), median (IQR) & 325 & $(91-435)$ & 298 & $93-427)$ \\
\hline HIV RNA (copies/mL), median (IQR) & $\begin{array}{r}58 \\
(21,250 \\
\end{array}$ & $\begin{array}{l}500 \\
-155,013) \\
\end{array}$ & $\begin{array}{r}48 \\
(16,750 \\
\end{array}$ & $\begin{array}{l}000 \\
139,000)\end{array}$ \\
\hline
\end{tabular}

$A R T=$ antiretroviral therapy; $H I V=$ human immunodeficiency virus; $I D U=$ injection drug use; $I Q R=$ interquartile range; $M H=$ mental health issues; $M S M=$ men who have sex with men; PTSD = posttraumatic stress disorder; $S A=$ substance abuse; SAMISS = substance abuse and mental illness screener.

Sixteen of the 28 participants (57.1\%) attended all follow-up visits, including the 6-month final follow-up visit. Four (14.3\%) of the remaining participants attended at least 1 follow-up visit, and 8 participants (28.6\%) did not attend any follow-up visits. Six of the patients who missed 1 or more follow-up appointments were reachable by telephone at the end of the study. The reasons cited by these participants for missing appointments centered around living and social issues. There were no statistically significant differences in patient-level characteristics between patients who completed and who did not complete the study.

\begin{tabular}{|c|c|c|c|c|}
\hline TA & \multicolumn{4}{|c|}{$\begin{array}{l}\text { Longitudinal Results for Patients Who } \\
\text { Completed Adherence Intervention } \\
(n=16)\end{array}$} \\
\hline & Baseline & $\begin{array}{c}\text { 6-Week } \\
\text { Follow-up }\end{array}$ & $\begin{array}{l}\text { 3-Month } \\
\text { Follow-up }\end{array}$ & $\begin{array}{l}\text { 6-Month } \\
\text { Follow-up }\end{array}$ \\
\hline \multicolumn{5}{|c|}{ CD4 count (cells/mm³) } \\
\hline Median & 298 & $387^{a}$ & $356^{b}$ & $454^{a}$ \\
\hline Interquartile range & $93-427$ & $176-492$ & $171-565$ & $181-654$ \\
\hline \multicolumn{5}{|l|}{ HIV RNA (copies/mL) } \\
\hline Median & 48,000 & $130^{\mathrm{b}}$ & $32^{b}$ & $0^{a}$ \\
\hline Interquartile range & $\begin{array}{l}16,750- \\
139,000\end{array}$ & $59-1743$ & $0-219$ & $0-0$ \\
\hline
\end{tabular}

Note: All comparisons between baseline and specified follow-up time point.

${ }^{a} P<0.001$.

${ }^{b} P<0.010$.

HIV=human immunodeficiency virus.

Findings from the longitudinal analysis of clinical outcomes for patients who completed all follow-up visits indicated statistically significant differences in CD4 counts and viral load levels between baseline and the 6-week, 3-month, and 6-month follow-up assessments (Table 2). Specifically, median CD4 count improved from 298 cells/mm3 (interquartile range $[\mathrm{IQR}]=93-427)$ at baseline to 454 cells $/ \mathrm{mm} 3(\mathrm{IQR}=81-654)$ at 6 months $(P=0.001)$, whereas median HIV RNA viral load decreased from 48,000 copies/mL $(\mathrm{IQR}=16,750-139,000)$ at baseline to all participants having an undetectable HIV RNA level at 6 months ( $<20$ copies $/ \mathrm{mL}, P=0.001)$.

The total cost of the adherence intervention as implemented (intention-to-treat cost) was $\$ 16,811$, or $\$ 1,050.68$ for each of the 16 patients who completed the intervention; noncompleters accounted for $22 \%$ of the intention-to-treat cost. The true mean cost per patient who completed the 5-visit intervention was $\$ 819.74$. This total includes $\$ 139.24$ in costs borne by patients and $\$ 680.50$ in clinic-borne costs. Compensation for pharmacists' time (\$528.86 per patient, on average) accounted for $78 \%$ of the total cost to the clinic for each patient who completed the adherence intervention.

The transmission rate modeling analysis indicated that the adherence intervention prevented approximately 0.134 secondary HIV infections among the sexual partners of the 16 PLWH who completed the full intervention during the 3 months following the 6-month assessment. The corresponding savings in averted future HIV-related medical care expenditures and lost QALYs were $\$ 49,702$ and 0.772 , respectively. Thus, the intervention was highly cost saving, with a return (savings-to-cost ratio) of \$2.96 in future medical care savings for each dollar spent on the intervention.

The results of the sensitivity and scenario analyses are summarized in Table 3. In the univariate sensitivity analyses, the smallest savings-to-cost ratio was obtained when the pharmacists' hourly compensation was set to $\$ 104.77$, which is $25 \%$ greater than the base-case value (\$83.78). This manipulation 
TABLE 3 Results of Adherence Intervention Net Cost Sensitivity and Scenario Analyses

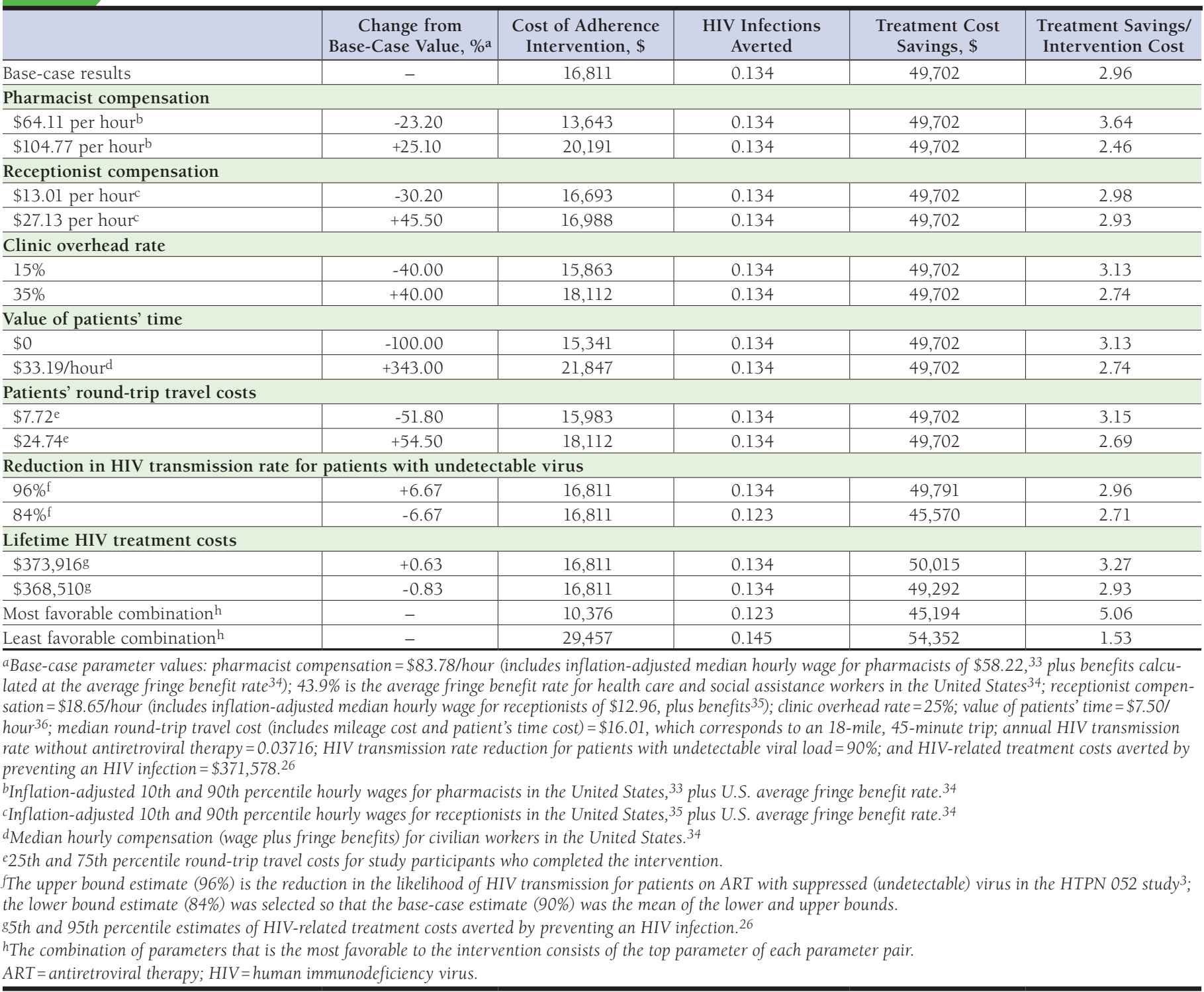

reduced the savings-to-cost ratio by $16.74 \%$, to 2.46 . In the least favorable scenario analysis (in which all parameters were set to the value that is least favorable to the intervention), the savings-to-cost ratio decreased to 1.53 , and in the most favorable scenario analysis, it increased to 5.06 .

The main analyses conservatively assumed that the 16 patients who completed the intervention (all of whom had undetectable virus at the 6-month follow-up visit) would remain virally suppressed during the following 3-month period, but no longer. If instead, all 16 patients remained suppressed for 6 months, the savings-to-cost ratio would increase to 5.92. Conversely, even with all parameters set to their least favorable value, the intervention would remain cost saving provided that patients remained virally suppressed for the 2 months following the 6-month visit.

\section{Discussion}

Multidisciplinary care teams, including care teams with pharmacists, have a positive effect on the ART adherence of HIV-infected patients. 29,30 This study evaluated the clinical and economic effects of an existing pharmacist-led adherence intervention in New Mexico, the results of which support the role of clinical pharmacists within multidisciplinary care teams working with HIV-infected patients.

Clinically, all participants who completed the study experienced virologic suppression. The positive clinical results 
observed in this study were likely a function of timing of the pharmacist visits before and shortly after ART initiation and the quantity of time pharmacists spent with patients. The 12 patients who did not complete the study were lost to follow-up from the adherence clinic, and no additional patientlevel data were recorded for these patients during the study period. The large number of patients who were lost to followup may be reflective of the high-risk patient population seen in the adherence clinic.

Early initiation and adherence to ART yield quality of life and survival benefits to PLWHs and reduce the chance of HIV transmission to other individuals. ${ }^{2,3}$ Therefore, obtaining ART adherence shortly after ART initiation is crucial. The adherence clinic was designed to ensure that pharmacists met often with patients following ART initiation. These initial visits allowed pharmacists to manage promptly any ART-related side effects or adherence barriers in order to secure optimal ART adherence from patients early in therapy. Standard of care for patients suggests that the first follow-up visit to check HIV viral load be within 2-4 weeks (and no later than 8 weeks) after ART initiation. ${ }^{1}$ However, this high-risk group of patients might have required more immediate adherence assistance and may not have received enough one-on-one time with their PCPs to address all of their questions or barriers. Early adherence counseling following ART initiation within the first month, in addition to adherence counseling before ART initiation, has been shown to improve ART adherence, as well. ${ }^{19}$

Pharmacists spent approximately 3 hours with each participant who completed the study over the course of 6 months, which is much more contact than most patients would have had with their PCPs. During these 3 hours, pharmacists used motivational interviewing techniques, which has been shown to increase ART adherence. ${ }^{31}$ Education and counseling before ART initiation by a pharmacist working as part of a multidisciplinary team also improved ART adherence. ${ }^{13}$ This intervention focused on lengthy counseling sessions involving medication and disease state education that emphasized participant recall rather than informational handouts. All pharmacists who participated in this study had training in infectious diseases pharmacotherapy and several years of experience working with HIV-infected patients. Pharmacists in this study addressed patients' social issues, such as homelessness or substance abuse, that could be barriers to adequate ART adherence. Pharmacists also helped providers select optimal, participantspecific ART regimens based on previous medication experiences of the patient and psychosocial issues. To improve comprehension of difficult adherence concepts, pharmacists used language appropriate for the participant's education level and repeated all of the ART adherence counseling points numerous times during each appointment.

In addition to the positive clinical effect, this intervention was highly cost saving, with a return of $\$ 2.96$ in future medical care savings for each dollar spent on the adherence intervention. The economic analyses were conducted on an intention-to-treat basis and therefore included costs (but no benefits) for the 12 patients who failed to complete the intervention. At a cost of $\$ 308$ per patient, these noncompleters accounted for $22 \%$ of the total cost of the intervention. This finding suggests that more intensive efforts to retain patients in clinic-based adherence interventions could be a cost-effective or cost-saving adjunct to these interventions.

Not only are pharmacists well positioned to administer a medication adherence intervention because of their unique skillset, but most are compensated at a lower rate than physicians, which further increases the cost-effectiveness of pharmacist-led adherence interventions. Under conservative assumptions of the durability of this intervention, the adherence clinic also showed significant prevention of HIV transmission to the partners of the adherence clinic participants. Given the relatively low cost of the intervention and the positive effect on the participant's virologic suppression and prevention of future transmission, we strongly recommend the inclusion of pharmacists on multidisciplinary care teams to improve patient ART adherence.

Although many medication adherence studies measure adherence directly as their primary outcome, this study used the more clinically relevant outcome of viral suppression. Viral suppression is a laboratory-based measure, is not subject to biases associated with self-reported medication adherence measures, and directly measures the health and infectiousness of a PLWH.

\section{Limitations}

This study has some limitations to consider. While this study demonstrates the positive effect of pharmacist medication adherence interventions on the viral load of HIV-infected patients, low external validity is a concern because of the single center study design. However, with an increasing number of pharmacists caring for HIV-infected patients in similar adherence clinics across the United States, our results should have strong external validity, unless our study participants were different from other U.S. HIV-infected patients, and/or pharmacists were not performing similar interventions in other clinics.

The sample size is also a limitation. THS underwent numerous changes during the course of this study, which decreased the number of patients referred to the adherence clinic for the 6 months of the study. These changes included a relocation of the clinic, a change in clinic administrative leadership and nursing, and support staff turnover. Also, because we relied solely on provider referral for study participation, it is possible that physicians were more likely to refer patients to the study if they felt they would be adherent following the intervention. Thus, it is possible that our results do not apply to all nonadherent patients, but only to the types of patients referred to the 
clinic by physicians. The number of patients who were lost to follow-up is a testament to how difficult it is to retain patients with documented adherence problems in HIV care. ${ }^{32}$

\section{Conclusions}

This study demonstrated that a pharmacist-led ART adherence clinic operating within a multidisciplinary care clinic can help HIV-infected patients with documented medication adherence problems achieve HIV viral suppression, which, in turn, decreases the likelihood of HIV transmission by these patients and leads to future savings in averted HIV-related treatment costs. In this study, the savings in future treatment costs far outweighed the cost of the pharmacist-led adherence intervention. Future large-scale studies should further investigate the effect of early and sustained pharmacist ART adherence interventions on patient health and HIV transmission. In addition, HIV clinics serving patients with ART adherence problems that do not employ a pharmacist should consider hiring a pharmacist to assist these patients with ART adherence.

\section{Authors}

THOMAS J. DILWORTH, PharmD, Department of Pharmacy Services, Aurora St. Luke's Medical Center, Milwaukee, Wisconsin. PAMELA W. KLEIN, PhD, Health Resources and Services Administration, HIVIAIDS Bureau, Rockville, Maryland. RENEEE-CLAUDE MERCIER, PharmD, PhC, BCPS-AQID; MATTHEW E. BORREGO, PhD; and BERNADETTE JAKEMAN, PharmD, BCPS, AAHIVP, Department of Pharmacy Practice and Administrative Sciences, University of New Mexico College of Pharmacy, Albuquerque, New Mexico. STEVEN D. PINKERTON, $\mathrm{PhD}$, Center for AIDS Intervention Research, Medical College of Wisconsin, Milwaukee.

AUTHOR CORRESPONDENCE: Thomas J. Dilworth, PharmD, Specialty Pharmacy Coordinator, Infectious Diseases, Department of Pharmacy Services, Aurora St. Luke's Medical Center, 2900 W. Oklahoma Ave., Milwaukee, WI 53215. Tel.: 414.649.6763;

E-mail: thomas.dilworth@aurora.org.

\section{DISCLOSURES}

This work was supported in part by a research grant to Dilworth, Mercier, and Borrego from the American Society of Health-System Pharmacists Foundation. Klein and Pinkerton were supported in part by grants T32MH19985 and P30-MH52776, respectively, from the National Institute of Mental Health. No funding bodies had any role in the study design, data collection, analysis, decision to publish, or preparation of the manuscript. The findings and conclusions in this article are those of the authors and do not necessarily represent the official position of the Health Resources and Services Administration. The authors have no conflicts of interest to disclose.
Study concept and design were contributed primarily by Dilworth Mercier, and Borrego, along with the other authors. Dilworth took the lead in data collection, along with Pinkerton, Klein, Mercier, and Jakeman. Data interpretation was performed by Dilworth and Pinkerton, along with the other authors. The manuscript was written by Dilworth, Klein, and Jakeman, with assistance from the other authors, and revised by Dilworth, Jakeman, and Klein, with assistance from the other authors.

The results from this study were presented in part at the 2015 United States Conference on AIDS in Washington, DC, on September 10-13, 2015.

\section{ACKNOWLEDGMENTS}

The authors thank Michelle Iandiorio, MD, and the other providers at Truman Health Services for referring patients to the adherence clinic. The authors also thank Deborah Parris, RN, and Lindsey Mascarenas, PharmD, for help scheduling follow-up appointments for participants enrolled in this study.

\section{REFERENCES}

1. Panel on Antiretroviral Guidelines for Adults and Adolescents. Guidelines for the use of antiretroviral agents in adults and adolescents living with HIV. Department of Health and Human Services. Updated October 17, 2017. Available at: http://aidsinfo.nih.gov/contentfiles/lvguidelines/Adultand AdolescentGL.pdf. Accessed January 10, 2018.

2. Lundgren JD, Babiker AG, Gordin F, et al. Initiation of antiretroviral therapy in early asymptomatic HIV infection. N Engl J Med. 2015:373(9):795-807.

3. Cohen MS, Chen YQ, McCauley M, et al. Prevention of HIV-1 infection with early antiretroviral therapy. N Engl J Med. 2011;365(6):493-505.

4. Bradley H, Hall HI, Wolitski RJ, et al. Vital signs: HIV diagnosis, care, and treatment among persons living with HIV - United States, 2011. MMWR Morb Mortal Wkly Rep. 2014;63(47):1113-17.

5. Paterson DL, Swindells S, Mohr J, et al. Adherence to protease inhibitor therapy and outcomes in patients with HIV infection. Ann Intern Med. 2000;133(1):21-30.

6. Kibicho J, Pinkerton SD, Owczarzak J, Mkandawire-Valhmu L, Kako PM. Are community-based pharmacists underused in the care of persons living with HIV? A need for structural and policy changes. J Am Pharm Assoc (2003). 2015;55(1):19-30.

7. Foisy MM, Akai PS. Pharmaceutical care for HIV patients on directly observed therapy. Ann Pharmacother. 2004;38(4):550-56.

8. Geletko SM, Poulakos MN. Pharmaceutical services in an HIV clinic. Am J Health Syst Pharm. 2002;59(8):709-13.

9. Guerrault MN, Leclerc C, Langevin S, Merian-Brosse L, Brossard D, Welker Y Study of the usefulness of pharmacist consultations for patients on antiretroviral regimens. Presse Med. 2005;34(20 Pt 2):1563-70 [Article in French].

10. Henderson KC, Hindman J, Johnson SC, Valuck RJ, Kiser JJ. Assessing the effectiveness of pharmacy-based adherence interventions on antiretroviral adherence in persons with HIV. AIDS Patient Care STDS. 2011;25(4):221-28.

11. March K, Mak M, Louie SG. Effects of pharmacists' interventions on patient outcomes in an HIV primary care clinic. Am J Health Syst Pharm. 2007;64(24):2574-78.

12. Rathbun RC, Farmer KC, Stephens JR, Lockhart SM. Impact of an adherence clinic on behavioral outcomes and virologic response in treatment of HIV infection: a prospective, randomized, controlled pilot study. Clin Ther. 2005;27(2):199-209.

13. Frick P, Tapia K, Grant P, Novotny M, Kerzee J. The effect of a multidisciplinary program on HAART adherence. AIDS Patient Care STDS. 2006;20(7):511-24.

14. Nevo ON, Lesko CR, Colwell B, Ballard C, Cole SR, Mathews WC Outcomes of pharmacist-assisted management of antiretroviral therapy in patients with HIV infection: a risk-adjusted analysis. Am J Health Syst Pharm. 2015;72(17):1463-70. 
15. Saberi P, Dong BJ, Johnson MO, Greenblatt RM, Cocohoba JM. The impact of HIV clinical pharmacists on HIV treatment outcomes: a systematic review. Patient Prefer Adherence. 2012;6:297-322.

16. Cope R, Berkowitz L, Arcebido R, Yeh JY, Trustman N, Cha A. Evaluating the effects of an interdisciplinary practice model with pharmacist collaboration on HIV patient co-morbidities. AIDS Patient Care STDs. 2015;29(8):445-53.

17. Carnevale RC, de Godoi Rezende Costa Molino C, Visacri MB, Mazzola PG, Moriel P. Cost analysis of pharmaceutical care provided to HIV-infected patients: an ambispective controlled study. Daru. 2015;23:13

18. Pence BW, Gaynes BN, Whetten K, Eron JJ, Ryder RW, Miller W. Validation of a brief screening instrument for substance abuse and mental illness in HIV-positive patients. J Acquir Immune Defic Syndr. 2005;40(5):434-44.

19. Chung MH, Richardson BA, Tapia K, et al. A randomized controlled trial comparing the effects of counseling and alarm device on HAART adherence and virologic outcomes. PLoS Med. 2011;8(3):e1000422. Available at: http:// journals.plos.org/plosmedicine/article?id=10.1371/journal.pmed.1000422. Accessed January 10, 2018.

20. Gold M, McCoy K, Siegel J. Cost-Effectiveness in Health and Medicine. New York: Oxford University Press; 1996.

21. U.S. General Services Administration. POV mileage rates (archived). February 2, 2016. Available at: https://hab.hrsa.gov/stateprofiles2014/? Accessed January 10, 2018.

22. U.S. Department of Health and Human Services, Health Resources and Services Administration. Ryan White HIV/AIDS program state profiles, 2012. Available at: https://hab.hrsa.gov/stateprofiles2014/?. Accessed January 10, 2018

23. Granich RM, Gilks CF, Dye C, De Cock KM, Williams BG. Universal voluntary HIV testing with immediate antiretroviral therapy as a strategy for elimination of HIV transmission: a mathematical model. Lancet. 2009;373(9657):48-57

24. Holtgrave DR. Estimation of annual HIV transmission rates in the United States, 1978-2000. J Acquir Immune Defic Syndr. 2004;35(1):89-92.

25. Wood E, Milloy MJ, Montaner JS. HIV treatment as prevention among injection drug users. Curr Opin HIV AIDS. 2012;7(2):151-56.

26. Pinkerton SD. HIV transmission rate modeling: a primer, review, and extension. AIDS Behav. 2012;16(4):791-96.
27. Farnham PG, Holtgrave DR, Gopalappa C, Hutchinson AB, Sansom SL. Lifetime costs and quality-adjusted life years saved from HIV prevention in the test and treat era. J Acquir Immune Defic Syndr. 2013;64(2):e15-18.

28. Pinkerton S, Holtgrave D. A method for evaluating the economic efficiency of HIV behavioral risk reduction interventions. AIDS and Behavior. 1998;2(3):189-201.

29. Fleishman JA, Yehia BR, Moore RD, Korthuis PT, Gebo KA.

Establishment, retention, and loss to follow-up in outpatient HIV care. J Acquir Immune Defic Syndr. 2012;60(3):249-59.

30. Horberg MA, Hurley LB, Towner WJ, et al. Determination of optimized multidisciplinary care team for maximal antiretroviral therapy adherence. J Acquir Immune Defic Syndr. 2012;60(2):183-90.

31. Hill S, Kavookjian J. Motivational interviewing as a behavioral intervention to increase HAART adherence in patients who are HIV-positive: a systematic review of the literature. AIDS Care. 2012;24(5):583-92.

32. Mizuno Y, Purcell DW, Knowlton AR, Wilkinson JD, Gourevitch MN, Knight KR. Syndemic vulnerability, sexual and injection risk behaviors, and HIV continuum of care outcomes in HIV-positive injection drug users. AIDS Behav. 2015;19(4):684-93. Available at: https://www.ncbi.nlm.nih.gov/pmc/ articles/PMC4636202/. Accessed January 10, 2018.

33. U.S. Department of Labor, Bureau of Labor Statistics. Occupational outlook handbook. Pharmacists. December 17, 2015. Available at: https://www. bls.gov/ooh/healthcare/pharmacists.htm. Accessed January 10, 2018.

34. U.S. Department of Labor, Bureau of Labor Statistics. News release. Employer costs for employee compensation-June 2015. September 9, 2015. Table 2, p. 7. Available at: http://www.bls.gov/news.release/archives/ ecec_09092015.pdf. Accessed January 10, 2018.

35. U.S. Department of Labor, Bureau of Labor Statistics. Occupational outlook handbook. Receptionists. December 17, 2015. Available at: https:// www.bls.gov/ooh/office-and-administrative-support/receptionists.htm. Accessed January 10, 2018.

36. New Mexico Department of Workforce Solutions. Minimum wage information. 2009. Available at: http://www.dws.state.nm.us/Labor-Relations/ Resources/Minimum-Wage-Information. Accessed January 10, 2018. 